\title{
Derechos humanos para el desarrollo de una sociedad realmente globalizada*
}

Recibido: 23 de julio de 2019 • Aprobado: 4 de septiembre de 2019

https://doi.org/10.22395/ojum.v19n38a2

\author{
Ana Claudia Santano*
}

\section{RESUMEN}

El mundo - tal y como lo conocemos- es resultado de una profunda transformación provocada por el fenómeno de la globalización. Sin embargo, lo que en sus inicios era solamente una estrategia para ampliar los mercados mundiales, terminó siendo un proceso integrador mucho más amplio de las sociedades que involucra aspectos políticos, culturales y sociales. En este sentido, se hace necesaria una nueva interpretación global de los derechos humanos. Este trabajo aborda, entonces, el tema de cómo evaluar la gobernanza constitucional pensada para una sociedad mundial. Para ello, se realizó una investigación doctrinal preliminar a fin de que se pueda introducir una nueva mirada a los sistemas jurídicos internacionales y nacionales para lograr una mayor concreción de los derechos humanos. Cada vez se hace más apremiante la tarea de consolidar los derechos humanos teniendo en cuenta la globalización como un hecho que permanecerá durante mucho tiempo.

Palabras clave: globalización; desarrollo; derechos humanos; sistemas multinivel; constitucionalismo.

* Este artículo se desarrolla en el marco de las actividades académicas de la autora, a partir de las reflexiones tenidas en el curso "Los enemigos de los derechos humanos", el cual se imparte en la Maestría y Doctorado en Derechos Fundamentales y Democracia del Centro Universitario Autónomo de Brasil, Curitiba, Paraná, Brasil.

** Licenciada en Derecho, especialista en Derecho Constitucional, maestra y doctora en Ciencias Jurídicas y Políticas. Estancia postdoctoral, Universidad Externado, Bogotá, Colombia. Profesora, Programa de Posgrado en Derechos Fundamentales y Democracia, Centro Universitario Autónomo de Brasil, Curitiba, Paraná, Brasil; profesora de Derecho Constitucional, Electoral, Parlamentario y Derechos Humanos en diversos cursos de grado y posgrado en Brasil y en el exterior. Correo electrónico: anaclaudiasantano@ yahoo.com.br. Orcid: https://orcid.org/0000-0002-0207-1510 


\title{
Human Rights for the Development of a Truly Globalized Society
}

\begin{abstract}
The world —as we know it - is the result of a profound transformation provoked by the globalization phenomenon. Nonetheless, what was initially a strategy for widening the world markets ended up being a much wider integrating process of the societies, that involved political, social and cultural aspects. In this direction, the necessity of a new global interpretation of the Human Rights is made evident. This work engages, then, the topic of how to evaluate the institutional governance thought for a worldwide society. For that, preliminary doctrinal research was undergone to introduce a new regard to the national and international judicial systems for achieving a greater concretion of human rights. The task of consolidating human rights taking globalization into account as a long-lasting fact is more urgent every day.
\end{abstract}

Keywords: globalization; development; human rights; multi-level systems; constitutionalism.

\section{Direitos humanos para o desenvolvimento de uma sociedade realmente globalizada}

\section{RESUMO}

O mundo — como o conhecemos - é resultado de uma profunda transformação provocada pelo fenômeno da globalização. Contudo, o que, em seu início, era somente uma estratégia para ampliar os mercados mundiais, acabou sendo um processo integrador muito mais amplo das sociedades que envolve aspectos políticos, culturais e sociais. Nesse sentido, é necessária uma nova interpretação global dos direitos humanos. Portanto, este trabalho aborda o tema de como avaliar a governança constitucional pensada para uma sociedade mundial. Para isso, foi realizada uma pesquisa doutrinária preliminar a fim de se poder introduzir uma nova visão dos sistemas jurídicos nacionais e internacionais para atingir uma maior concretização dos direitos humanos. Cada vez mais, faz-se urgente a tarefa de consolidar os direitos humanos considerando a globalização como um fato que permanecerá por muito tempo.

Palavras-chave: globalização; desenvolvimento; direitos humanos; sistemas multinível; constitucionalismo. 


\section{INTRODUCCIÓN}

En los últimos años se ha presenciado - y vivido- un proceso transformador profundo de las sociedades, no solamente en el campo económico, sino también en la manera de interactuar con otros países y con otras personas; en los conceptos sobre el mundo y la vida. Todo esto fue provocado especialmente por el enorme fenómeno llamado globalización.

Para considerar este breve punto de inicio, el tema principal de este ensayo se enfoca en el mundo globalizado y la gobernanza constitucional. Para ello, después de (i) introducir lo que se entiende como globalización (concepto que es difícil definir en pocas líneas), (ii) se habla sobre su influencia en la construcción de las constituciones, elaboración y específicamente la interpretación de sistemas constitucionales en un ambiente globalizado de relaciones económicas, sociales y culturales; (iii) luego se pasa a la influencia de la protección internacional de los derechos humanos en los sistemas constitucionales nacionales, considerando el sistema universal e interamericano de derechos humanos. (iv) Siguiendo esta línea, se aborda muy brevemente el sistema jurídico multinivel y se considera el derecho doméstico y el internacional en la dirección del Ius Constitutionale Commune en el mundo globalizado, tema muy debatido en Latinoamérica. (v) Finalmente, se provoca la reflexión sobre esta eventual "nueva era" que estamos viviendo actualmente. ¿El mundo globalizado es una realidad o estamos regresando a sistemas nacionalistas?

\section{GLOBALIZACIÓN. ¿QUUÉ ES ESO?}

Es imposible negar la influencia de la globalización en la vida diaria y también es difícil creer que simplemente se pueden desconsiderar sus efectos para planear el futuro a corto o largo plazo (eso no importa). El punto central es que la globalización vino para quedarse. Quizá quitarla o retirarla de la dinámica del mundo actual puede ser mucho peor que su adecuación para lo que se objetiva como sociedad (Beck, 2008). En este sentido, se hace necesario que los Estados en el mundo colaboren y dialoguen para que puedan manejar y pensar los problemas que tienen en común, tales como la contaminación del medio ambiente, prevención y combate de los delitos internacionales y terrorismo, así como la efectiva cooperación en la esfera de la protección de los derechos humanos (Konhad Adenauer Stiftung, 2001).

De acuerdo con el marxismo, el desarrollo social depende del crecimiento económico (Marx, 2003, p. 18), y esta posición contiene la importancia de un sistema jurídico en el desarrollo propio de un Estado. Particularmente, con la creciente relevancia de la Organización Mundial del Comercio, la globalización económica basada en el mercado global eleva a los Estados en la esfera de la ideología y del sistema jurídico. Cabe subrayar que después de la Segunda Guerra Mundial, las Naciones Unidas tuvieron un rol muy relevante en la promoción del desarrollo de la globalización y de la 
cooperación entre diferentes civilizaciones, especialmente en el dominio de la protección de los derechos humanos y del Estado de derecho (Marx, 2003, p. 38 y ss.).

En esta línea, la globalización no es solamente un concepto teórico, sino práctico en muchos países como Brasil y otros Estados latinoamericanos, en China, India, entre otros. Su importancia en la vida pública ha aumentado, principalmente en el campo de la construcción constitucional. Las ideas sobre democracia, libertad, derechos humanos y Estado de derecho fundamentadas en los ejes de la globalización han cambiado profundamente las reformas políticas y la construcción jurídica y legal de muchos lugares del mundo (Bauman, 1999).

El concepto de globalización no es muy claro. Como ya se ha dicho antes, para la academia y la literatura ha sido un reto explicarlo. Sin embargo, hay algunos elementos que pueden ayudar a identificar su evolución histórica y su significado principal.

El origen de la globalización viene desde el colonialismo capitalista en la forma de entrada y salida de capital internacional con el objetivo de no tener que soportar más costes sociales (Habermas, 2001, p. 53 y ss.). Aunque Bauman (1999, p. 13 y ss.) sostenga que el nacimiento de la globalización actual dio lugar al proceso de formación de las Naciones Unidas, las cuales han fomentado y fortalecido la cooperación y el diálogo entre los Estados nacionales y han promocionado el desarrollo de la protección de los derechos humanos por medio de una serie de convenciones y tratados internacionales de derechos humanos desde 1948, su pilar principal es principalmente económico y lucrativo. Los otros elementos que componen la sociedad, como la propia integración de las personas, no se consideran.

En este sentido, parece más acertado adherir el concepto de globalización aportado por Álvaro Jarillo Aldeanueva (2001), quien entiende este concepto como un proceso en el que las sociedades están alterando relaciones de toda clase como una resultante de un mundo que está conectado. Este hecho también se refleja en la difuminación de las fronteras y su sentido clásico de Estados nación. Así, este fenómeno se muestra maleable y en constante movimiento.

La categoría y la extensión de la globalización no están definitivamente acabadas, justamente por su maleabilidad. Particularmente esta idea no trae dentro de sí factores legales, sociales y políticos (Beck, 2008, p. 91 y ss.). En este sentido, son innegables los efectos de la globalización en algunos países donde sus sociedades son muy plurales en lo que se refiere a la nacionalidad de las personas que trabajan y producen bienes para el crecimiento de la economía en sus regiones de residencia. Asimismo, es muy visible la globalización de la democracia y de los partidos políticos en los Estados nacionales en tanto muchas causas políticas son comunes en 
distintos países. Las organizaciones partidistas fueron creadas debido a este fenómeno global, como lo es el movimiento verde para la defensa del medio ambiente del planeta, lo cual hace común esta ideología en muchos lugares. En el presente, el mejor ejemplo de esto es el Partido Verde', pues ha jugado un rol muy importante en el proceso de las elecciones generales de muchos Estados, incluyendo la Unión Europea. Allí existe el Partido Verde Europeo, el cual está compuesto por muchos otros partidos verdes nacionales en los Estados miembros².

Los problemas sociales también están globalizados en el sentido de una mundialización, tal como explica Martínez Morán (2008), considerado un proceso civilizatorio, un espacio común resultante del mismo proceso ocurrido en la economía tratada como algo global. La pobreza, falta de oportunidades, desigualdades, entre otras cuestiones, no solo son muy comunes porque muchos gobiernos son ineficientes para alcanzar sus objetivos, sino también porque este fenómeno internacional facilitó el crecimiento de las desigualdades y la explotación de trabajadores. Paralelamente, se dio la evasión del pago de impuestos de las multinacionales con los Estados nacionales por, con lo que disminuyeron los recursos económicos que sirven para luchar en contra de estos problemas sociales y para elaborar políticas públicas eficientes. Sobre estas cuestiones, se pueden mencionar muchos ejemplos recientes que demuestran cómo un problema social nacional puede ser considerado un problema globalizado, como es el caso de la caravana migrante que ocurrió entre 2018 y 2019 en la frontera entre los Estados Unidos y México ${ }^{3}$. Este trágico evento muestra cómo la violencia urbana, la pobreza, la ilimitada exploración de los recursos humanos y la corrupción sistémica de la administración pública pueden afectar a muchos otros países, más allá del que padeció, inicialmente estas problemáticas. En el ejemplo citado hay más de tres mil personas, migrantes centroamericanos, que han llegado a la frontera mexicana por la ciudad de Tijuana, después de cruzar México y partes de la América Central. Sus vidas se han vuelto precarias por las condiciones económicas y sociales en Honduras, Guatemala y El Salvador debido a la presencia y acción de las pandillas criminales y la violencia urbana que ello conlleva ${ }^{4}$, así como la falta de oportunidades y de alternativas en sus países de origen (BBC News, 2018).

1 El Partido Verde se hace presente en distintos países europeos como Alemania, España y Austria. Su principal agenda en común es la responsabilidad ambiental. Y no se ubica solamente en Europa, sino que también tiene sus "representantes" en América Latina, como Colombia y Brasil. Sobre este tema puede verse Barros (2018).

2 Para informaciones sobre el Europartido Verde, se recomienda consultar el enlace https://europeangreens.eu/ y sobre los europartidos en general, se puede consultar Santano y Pereira (2015).

3 La caravana migrante fue un movimiento de migración masiva de personas venidas principalmente de países centroamericanos, como Guatemala, Hondura y El Salvador. Aunque no sea la primera movilización de larga escala con este propósito, el episodio ganó notoriedad por las reacciones tenidas en México y en los Estados Unidos ante este desplazamiento (Martínez Hernández-Mejía, 2018).

4 Sobre el tema de las pandillas en Centroamérica, se recomienda leer a Aguilar y Carranza (2008). 
Este es un problema globalizado, no solo porque involucra a un grupo de países, sino también porque dependiendo de qué se haga y de cómo se proceda en la solución de este caso, puede inspirar o ser realizado en otros lugares del mundo que enfrentan la problemática de los refugiados, como Myanmar y Bangladesh con el caso de los Rohingyas (UN News, 2018) o como sucede con europeos, africanos y sirios que huyen de guerras y carecen de recursos vitales, como el agua (Black, 2001). Aparentemente, hay una sectorización de temas que en realidad son globales e interesan a todos los seres humanos, considerados a partir de una noción interdependiente no solo en sus derechos, sino también en su existencia y convivencia (Sánchez Lorenzo, 2017).

De esta forma, se entiende que la globalización no puede ser considerada solamente como una cuestión económica. Es algo mucho más complejo y profundo que involucra cuestiones políticas, económicas, sociales y culturales. En este sentido, es necesario pensar este fenómeno desde el punto de vista jurídico para integrar ordenamientos vigentes en la búsqueda de soluciones comunes para problemas semejantes. Por medio de estas normativas compartidas, se comparten valores, ya que se está tratando de seres humanos que son iguales entre sí.

¿Cómo se puede pensar en la globalización desde el punto de vista jurídico? (Rodríguez Martínez, 2012). En este artículo se sugiere empezar desde las constituciones.

\section{GLOBALIZACIÓN Y CONSTITUCIONALISMO}

La visión tradicional de la creación del constitucionalismo viene desde las escuelas académicas de la soberanía popular en forma de la base teórica del derecho para elaborar una constitución. La identidad del objeto de la elaboración de la constitución determina el proceso concreto de aceptación de la voluntad popular que conforma el contenido del derecho constitucional (Laclau, 2014).

En los primeros momentos de la conformación de las cartas constitucionales, muchos países decidieron adherirse al modelo de constitución de los Estados Unidos, Francia o Inglaterra. En el proceso de ingeniería para la elaboración de una constitución, varios países han aprendido uno del otro, lo que hace que la reciprocidad en esta dinámica sea obvia. Sin embargo, en las sociedades modernas, a partir de la base del sistema de protección de derechos humanos, una serie de convenciones e instrumentos internacionales generó un fuerte impacto en la elaboración de constituciones de los Estados miembros. A su vez, los valores universales sobre la protección de los derechos humanos han sido aceptados en distintos sistemas de derecho constitucional que terminaron reflejándose, por ejemplo, en otras esferas del constitucionalismo, como es la considerada Constitución de la Unión Europea, 
más conocida como Tratado de Lisboa. La manera de elevar dichos valores a una posición supranacional, identificando puntos en común y determinando la aplicación de reglas de mismo valor axiológico en distintos países, causó un enorme impacto en los Estados miembros de la Unión Europea. La forma en que se construyó este texto, que tenía la pretensión de ser una carta constitucional, abrió espacio para una nueva percepción sobre la estructuración de reglas constitucionales a partir de un paradigma transnacional por medio del proceso político de elaboración constitucional (Bauman, 1999; Habermas, 2002).

En este sentido, realmente es muy difícil encontrar constituciones con pocos o ningún dispositivo sobre derechos humanos. La tendencia es todo lo contrario: todas las cartas constitucionales en el mundo se están adhiriendo a sus contenidos humanistas progresivamente — en mayor o menor grado — y añadiendo reglas sobre derechos humanos que hacen de ello un proceso global. La integración de países en la esfera internacional fortalece la protección - y la responsabilidad — en relación con los derechos humanos. Todos los Estados miembros de organizaciones internacionales tienen la obligación de respetar los tratados que ellos optaron por ratificar voluntariamente. Esta relación —basada en el principio de la pacta sunt servandaobliga a los países, después de firmar y ratificar los instrumentos internacionales, a cumplir estrictamente con sus objetivos que resultan, en el mismo momento, de la necesidad de adaptar si es necesario o de hacer esfuerzos expresivos y razonables para alcanzar todos los puntos acordados relacionados con los derechos humanos (Almeida y Pereira, 2013).

Al considerar esto, es visible que la tendencia de la protección internacional de los derechos humanos ha impuesto una presión y generado un impacto importante en la elaboración constitucional de muchos países. En Brasil, por ejemplo, la Constitución de 1988 ha estado ampliamente fundamentada en los derechos humanos y en la dignidad de la persona humana, y fue promulgada después de un largo período de dictadura militar. Dicho proceso no va a parar y los académicos tienen que encargarse de lidiar con esta nueva manera de pensar desde un nuevo derecho constitucional global (Vásquez, 2009)5 .

\section{LA INFLUENCIA DE LA PROTECCIÓN INTERNACIONAL DE LOS DERECHOS HUMANOS EN LOS SISTEMAS CONSTITUCIONALES NACIONALES}

Los derechos humanos emergieron en el momento en que se verificaron tratos inhumanos en las guerras mundiales. En el inicio del siglo XX, las organizaciones internacionales de trabajo y otros organismos internacionales tuvieron un rol muy importante en la protección de los derechos humanos, principalmente en el campo de las minorías y los derechos laborales.

Este fenómeno es muy bien tratado por Neves (2009). 
Después de la Segunda Guerra Mundial se consideraron las lecciones de "no hacer" provenientes de las autoridades fascista de Italia y nazistas de Alemania, en lo que se refiere a la violación de los derechos humanos y en la desconsideración de la dignidad humana. A partir de esta consideración, la Declaración Universal de los Derechos Humanos fue adoptada y proclamada por la Asamblea General de las Naciones Unidas (1948) con la Resolución 217A (III). Este documento estableció la protección de los derechos humanos, que deberían ser igualmente aplicables para todos sin distinción de raza, color, género, idioma, religión, posición política o cualquier otra opinión, origen nacional o social, propiedad y estrato, lugar de nacimiento u otro criterio discriminatorio.

A partir de los dispositivos de la Declaración Universal de los Derechos Humanos, en tanto el Pacto Internacional de Derechos Civiles y Políticos como el Pacto Internacional de Derechos Económicos, Sociales y Culturales, fueron adoptados y abiertos para la firma, ratificación y consentimiento por la Asamblea General de las Naciones Unidas (1966) por medio de la Resolución 2200 A (XXI). En el período subsecuente, el protocolo facultativo del Pacto Civil fue aprobado e inició su vigencia en los países que lo ratificaron para posibilitar la presentación de quejas y peticiones individuales por medio de un mecanismo de monitoreo. Aún, a través de dicho protocolo, los Estados miembros están de acuerdo en reconocer la jurisdicción del Comité de Derechos Humanos de las Naciones Unidas para considerar quejas y peticiones de individuos que denuncian violaciones de derechos protegidos por el Pacto Civil. Los demandantes deben haber agotado antes todos los recursos domésticos de quejas. Las peticiones anónimas no serán admitidas. Hasta el día de hoy, dichos instrumentos internacionales constituyen el marco jurídico de la protección internacional de derechos humanos.

Otro protocolo facultativo está relacionado con el Pacto Internacional de Derechos Económicos, Sociales y Culturales, aprobado apenas en el año 2008 debido a su contenido muy "polémico" entre los Estados miembros, que se refieren más a la segunda dimensión de los derechos ${ }^{6}$. Como en el protocolo facultativo del Pacto Civil, este también establece un mecanismo de quejas y peticiones individuales sobre los derechos listados en el Pacto Económico. Además, los Estados miembros reconocen la jurisdicción del Comité para los Derechos Económicos, Sociales y Culturares, para que este analice las denuncias presentadas por individuos sobre la violación de estos derechos. En ambos instrumentos, las reglas también incluyen mecanismos de investigación: las partes deben haber permitido que el Comité investigue, reporte y haga

6 Aunque su desarrollo haya iniciado en el constitucionalismo mexicano en 1917 y en el constitucionalismo alemán en 1919 a partir de la Constitución de Weimar, dichos derechos todavía carecen de una completa validación, reconocimiento y realización por razones principalmente ideológicas debido a su contenido, que surgió específicamente de las "profundas contradicciones sociales resultantes de la aplicación de los valores liberales, cuyas formulaciones abstractas, descontextualizadas, fueron luego desenmascaradas" (Valim, 2011. p. 173). 
recomendaciones sobre violaciones del Pacto. Sin embargo, los Estados miembros pueden reservar dicha cláusula en el momento de la firma y ratificación para evadir la obligación, lo que puede impactar en la protección de estos derechos y en los principales objetivos de los pactos (Asamblea General de Naciones Unidas, 2008), algo que es muy criticado por autores como Augusto Cançado Trindade (1997).

Lo mismo se puede decir sobre el Sistema Interamericano de Derechos Humanos (SIDH), el cual es regional y es responsable del monitoreo, promoción y protección de los derechos humanos en los treinta y cinco países independientes de las Américas que son miembros de la Organización de los Estados Americanos (OEA).

El SIDH está compuesto por dos entidades principales: la Comisión Interamericana de Derechos Humanos (CIDH) y la Corte Interamericana de Derechos Humanos (Corte IDH). Ambos organismos pueden decidir quejas y peticiones individuales relativas a violaciones de derechos humanos y pueden dictar medidas protectoras emergentes cuando un individuo o un objeto de una queja se encuentran en inmediato riesgo de daño irreparable. La CIDH también se hace cargo de distintos procesos de monitoreo de derechos y de promoción de actividades de fomento, mientras que la Corte IDH puede emitir opiniones consultivas sobre temas que se relacionan con la interpretación de los instrumentos interamericanos de derechos humanos tanto por solicitud de la OEA como de un Estado miembro (IJRC, s.f.).

Dentro del SIDH, otros organismos se enfocan en derechos específicos o en grupos de derechos. Esto incluye a la Comisión Interamericana de las Mujeres (CIM), los grupos de trabajo en el Protocolo de San Salvador (tratado sobre los derechos sociales) y las diversas relatorías temáticas de la Comisión Interamericana de Derechos Humanos (Gorczevski y Dias, 2012).

Fundada por la OEA por resolución de la "Quinta Reunión de Consulta de Ministros de Relaciones Exteriores en Santiago de Chile en 1959" (OEA, s.f.), la Comisión Interamericana de Derechos Humanos empezó a operar en 1960. Su objetivo es observar las condiciones de los derechos humanos a través de visitas in loco, y en 1965 fue autorizada a procesar quejas y peticiones específicas de violación de derechos humanos. Los Estados miembros de la OEA reconocieron a la CIDH como el principal organismo de derechos humanos por medio de un protocolo a la Carta de la OEA, el cual se adoptó en 1967 e inició su vigencia en 1970 (IJRC, s.f.).

Además de organizar visitas a los países y de recibir quejas y peticiones, la CIDH también se encarga de estudios temáticos en puntos específicos. Publica informes y estudios, solicita la adopción de medidas de precaución para la protección de individuos en riesgo y elabora muchos dosieres con mayor profundización para monitorear 
determinados derechos humanos individuales o comunitarios en el hemisferio (IIRC, s.f.; Cambiaghi y Vannuchi, 2013).

Individuos, grupos de individuos y organizaciones no gubernamentales reconocidas en cualquier Estado miembro pueden presentar quejas o peticiones relacionadas con violaciones de derechos humanos, previstas tanto en la Declaración Americana de Derechos y Deberes del Hombre, como en la Convención Americana de Derechos Humanos (tratado sobre derechos civiles y políticos), y otros instrumentos regionales de derechos humanos. Años tras año, la CIDH recibe cada vez más peticiones. En el año 2016 llegó a 2.567 denuncias y en 2017 a 2.494. Son cifras bastante expresivas si se compara con los noventa cuando había alrededor de quinientos cincuenta denuncias al año (CIDH, 2017).

Por otro lado, la Corte Interamericana de Derechos Humanos es el órgano judicial del Sistema Interamericano de Derechos Humanos. Sus potestades son más limitadas que las de la Comisión porque la Corte IDH únicamente puede decidir casos previamente analizados por la CIDH en relación con los Estados miembros de la OEA que expresamente hayan aceptado su jurisdicción. De esta manera, solamente los Estados miembros y la propia CIDH pueden presentar casos ante la Corte IDH (IIRC, s.f.)

Los siete jueces de la Corte IDH son independientes, aunque elegidos por los Estados por medio de la Asamblea General. Su periodo de mandato es de seis años con la posibilidad de una reelección (IJRC, s.f.).

Actualmente, veinticinco Estados miembros de la OEA han ratificado la Convención Americana de Derechos Humanos. Veintidós de ellos aceptaron la jurisdicción contenciosa de la Corte IDH, de acuerdo con el art. 62 del Pacto de San José. Sin embargo, en 2012 Venezuela denunció la Convención y decidió no someterse más a ella después de algunas sentencias de la Corte IDH que condenan al país por distintas violaciones de derechos humanos ${ }^{7}$. Igualmente, Trinidad y Tobago denunció la Convención. Hasta el día de hoy ha seguido contrariado por distintas sentencias sobre la pena de muerte y su aplicación, de las cuales destaca el caso Caesar vs. Trinidad y Tobago (Corte IDH, 2015). En la misma línea, el 9 de julio de 1999, durante el

7 La información completa sobre firmas y ratificaciones puede ser encontrada en el enlace http://www. oas.org/dil/treaties_B-32_American_Convention_on_Human_Rights_sign.htm. Además, la OEA ya se pronunció oficialmente sobre esta decisión de Venezuela, y expresó su preocupación en el comunicado que está en el enlace http://www.oas.org/es/cidh/prensa/comunicados/2012/117.asp. La decisión de Venezuela fue motivada por un malestar entre este país y la OEA tras muchos casos de condena. Según noticia constante en el periódico El País, "desde 1995, la Corte Interamericana ha emitido 16 sentencias contra el Estado venezolano, por su responsabilidad en el asesinato de 18 pescadores a manos de militares en 1988, en el caso conocido como El Amparo; por la represión de la revuelta popular de 1989 conocida como El Caracazo; por la desaparición forzada y el asesinato de decenas de reclusos en el retén de Catia en 1992; y por vulnerar la labor de los medios con el cierre del canal Radio Caracas Televisión en 2007. Aunque algunos de estos episodios ocurrieron antes del Chavismo, que comenzó en 1998, muchos de los soldados y policías hallados responsables de muertes, torturas o desapariciones de entonces, eran generales y comandantes durante el régimen" (Primera, 2013). 
gobierno de Alberto Fujimori, Perú intentó retirar su adhesión a la competencia de la Corte Interamericana, pero el 24 de septiembre de 1999 se dictó una sentencia sobre competencia en la que se estableció que "el pretendido retiro, con efectos inmediatos, por el Estado peruano, de la declaración de reconocimiento de la competencia contenciosa de la Corte Interamericana de Derechos Humanos es inadmisible" (Corte IDH, 1999) . Esta decisión se fundamentó en el hecho de que el Pacto de San José de Costa Rica establece la posibilidad de denuncia, pero no hay previsión sobre el retiro del reconocimiento de la competencia de la Corte IDH (Rivero, 2013).

La Corte empezó a operar en 1979, y luego emitió sus primeras opiniones consultivas, aunque solo vino a ejercer su potestad contenciosa a partir de 1986, cuando la CIDH sometió el primer caso Velásquez Rodríguez vs. Honduras, en el que se profirió su primera sentencia de mérito en 1988 (IIRC, s.f.).

En las décadas de funcionamiento de la Corte IDH, el número de casos presentados fue superior al doble, pues muchos Estados aceptaron someterse a su jurisdicción. Además, este órgano adjudicó un gran número de derechos protegidos por la Convención Americana y demás tratados en los que se tratan temas que van desde ejecuciones extrajudiciales y casos de desaparición forzada de personas hasta derechos laborales, sobre la tierra y libertad de expresión, entre otros.

Cabe subrayar que las convenciones internacionales de derechos humanos han influido mucho en el proceso de elaboración constitucional y de creación de políticas en el campo de protección de derechos humanos en los Estados miembros. Muchos de ellos han aceptado integralmente la visión universal de los derechos humanos afirmada en dichos instrumentos internacionales. El estándar común de protección de derechos humanos para todas las personas y todas las naciones, como se ha detallado en la Declaración Universal de Derechos Humanos, ha sido establecido tanto entre los ciudadanos de los Estados miembros como entre los territorios que se encuentran bajo su jurisdicción (Neves, 2003).

En el proceso de aceptación de las visiones universales de derechos humanos hay muchas y valiosas contradicciones que necesitan ser resueltas tanto en el sentido teórico como en el práctico. El punto más importante es la relación entre las convenciones internacionales de derechos humanos y las leyes de protección de derechos humanos en los Estados miembros, particularmente en lo que se refiere a la manera de conexión entre los derechos humanos universales y aquellos protegidos por las leyes internas de los Estados miembros (Konhad Adenauer Stiftung, 2001).

Por ello, se hace necesario debatir esta relación entre las convenciones internacionales de protección de derechos humanos y las leyes internacionales en los Estados miembros. Esencialmente, se debe cuestionar sobre la relación entre el Estado de derecho y la protección de derechos humanos. Sin la conformidad o un tipo de con- 
senso entre las leyes internacionales y nacionales y sus principios ante el imperio de la ley, los valores de los derechos humanos pueden volverse más blandos debido al gran número de contradicciones entre Estados miembros y otros, que quizás no se resuelvan pacíficamente (Konhad Adenauer Stiftung, 2001).

Se hace muy importante en el nivel de los Estados nacionales que dicho diálogo y entendimiento mutuo pueda establecer consensos, para que todos los países puedan ser respetados e incentivados en el campo de la protección de los derechos humanos.

\section{EL SISTEMA JURÍDICO MULTINIVEL Y LAS LEYES INTERNACIONALES Y NACIONALES, EN LA DIRECCIÓN DE UN IUS CONSTITUTIONALE COMMUNE}

El monismo y el dualismo fueron originalmente concebidos como dos teorizaciones opuestas de la relación entre el derecho doméstico y el internacional. Fueron objeto de considerable debate en la primera mitad del siglo XX. Ambos son considerados por muchos académicos como una explicación limitada como teorías porque no logran alcanzar la forma que el derecho internacional funciona entre los Estados en la práctica (Chiam, 2018). Según Paola Andrea Acosta Alvarado (2016), la teoría dualista tiene que ver con que la jerarquía entre las normas depende de cómo la regla internacional sea integrada al ordenamiento interno. La teoría monista, por su lado, se conecta a un ordenamiento jurídico único que no tiene la necesidad de un proceso de integración de la norma internacional a la normativa interna.

Aunque existan críticas, monismo y dualismo todavía sirven como herramientas analíticas. Ellos actúan como puntos de partida consistentes para el examen de las relaciones entre el derecho doméstico y el internacional (Toro Huerta, 2005). Por ejemplo, los académicos de la esfera del derecho internacional que trabajan en el derecho doméstico o el derecho de la Unión Europea y el camino en que las cortes nacionales incorporan derechos humanos internacionales continúan usando el monismo y el dualismo como piedra de toque para este análisis. Muchas decisiones recientes en cortes domésticas hicieron que algunos académicos revivieran el monismo y el dualismo como potenciales canales para entender la argumentación judicial interna de los países sobre derecho internacional (Chiam, 2018).

Monismo y dualismo también proveen un atajo que señala actitudes de individuos e instituciones entre los sistemas de derecho interno ante el derecho internacional. En su forma más directa, el principal defensor del monismo Hans Kelsen (1965) y en este sentido también Losano (2002) consideraban que había una relación jerárquica entre el sistema legal monista, en el que el derecho internacional debería ser superior al derecho interno y, debido a ello, las normas internacionales deberían prevalecer en caso de conflicto entre los dos sistemas. A su vez, el sistema dualista trata el derecho 
internacional y el doméstico como esferas separadas e independientes. La validez del derecho internacional en un sistema dualista interno es determinada por la regla del derecho doméstico que autoriza la aplicación de la norma internacional. Considerando la variedad de formas en las que sistemas nacionales incorporan el derecho internacional, algunos académicos han preferido utilizar el término pluralismo en lugar de dualismo, incluso porque hay muchas manifestaciones de monismos y dualismos que escapan de las definiciones puras ya mencionadas (Chiam, 2018).

De hecho, una de las principales críticas de ambas teorías es que no hay sistemas nacionales que sean estrictamente monistas o dualistas. Al contrario, el derecho internacional puede ser tratado a partir de una variedad de formas por distintas instituciones de un país. Por ejemplo, las cortes nacionales pueden valerse de las leyes internacionales que los parlamentos no hacen. En este sentido, un Estado puede autorizar la directa incorporación de normas internacionales originadas desde el derecho consuetudinario, o bien pueden solicitar tratados internacionales para que se transformen en derecho doméstico antes de que tengan efectos directos en el ámbito interno del Estado. La literatura sobre monismo y dualismo puede ser dividida en dos tipos: exposiciones teóricas sobre los conceptos y análisis que toman el monismo y el dualismo como puntos de partida para la crítica. Eventualmente, pueden ser combinados con la exposición de la práctica del derecho internacional entre los países (Crawford, 2012).

Para alcanzar todos los objetivos relacionados con la protección de los derechos humanos, se sugiere superar este problema teórico y manejar el monismo y el dualismo como algo de menor relevancia ante la realidad de un mundo globalizado (Alvarado, 2016). Como se ha dicho anteriormente, es necesario fomentar el diálogo entre los países, entre las naciones, entre sistemas jurídicos y, principalmente, entre las constituciones de estos Estados. Para ello, se considera que el concepto de Ius Constitutionale Commune es un gran comienzo (Piovesan, 2017).

La noción de Ius Constitutionale Commune nació en América Latina, a partir de muchos estudios sobre el sistema interamericano de protección de los derechos humanos, principalmente sobre su impacto y resultados en los sistemas constitucionales de los países de América Latina. Aunque este concepto haya sido idealizado dentro de la realidad de esa región, quizás sea posible pensarlo considerando otras regiones del mundo, teniendo en mente justamente este perfil globalizado del mundo donde se vive en el siglo XXI.

De acuerdo con Armin Von Bogdandy et al. (2016), Ius Constitutionale Commune para América Latina tiene, en primer lugar, una función analítica, incluso ontológica. Se puede mencionar como un nuevo fenómeno jurídico, compuesto de elementos venidos desde muchos ordenamientos legales que están unidos por un impulso, un sentido 
en común, llamado constitucionalismo transformativo. Ius Constitutionale Commune para América Latina conecta la Convención Americana de Derechos Humanos, otros tratados e instrumentos, las garantías contenidas en las constituciones nacionales, las cláusulas constitucionales de apertura para el derecho interno de las normas internacionales, así como la jurisprudencia pertinente en el ámbito nacional e internacional. Para mencionar solamente un ejemplo de lo que esto significa, la comprensión legal de la Corte Interamericana de Derechos Humanos cambia cuando se parte de la idea de una institución internacional aislada en la República de Costa Rica a la idea de que es la institución que más nutre y alimenta la red latinoamericana del constitucionalismo transformativo. Dicha red conecta la Corte IDH a las cortes nacionales y otros tribunales internos (Von Bogdandy et al., 2016).

En segundo lugar, según Von Bogdandy et al. (2016), Ius Constitutionale Commune para América Latina tiene una función normativa. Esto fundamenta un sentido específico del proyecto del constitucionalismo transformativo que se siguió después de los regímenes autoritarios habidos en la región. Esto objetiva la expansión de la realización regional garantizada por las promesas centrales de las constituciones nacionales y retrata los esfuerzos de muchos países en una estructura de ayuda mutua como la llave del éxito de esta tarea de integración de normativas. Esto debería ayudar a difundir los estándares de los derechos humanos, compensando déficits nacionales y fomentando nuevas dinámicas de empoderamiento entre los actores sociales.

En tercer lugar, Ius Constitutionale Commune para América Latina designa también una aproximación académica, una mentalidad comparativa y una orientación metodológica direccionada a los principios, particularmente en la tríada derechos humanos, democracia y Estado de derecho. Esta lógica es incremental y los derechos son el principal enfoque e instrumento (Von Bogdandy et al., 2016).

Las tres dimensiones de Ius Constitutionale Commune para América Latina muestran que la creación, el desarrollo y la propagación de este concepto es consecuencial, y que esto tiene que ser así porque trata de impactar la realidad. El derecho es una construcción social. La terminología utilizada por los juristas, las cortes y los académicos del derecho, no está por fuera de las normas, sino que es constitutiva de ellas. Es esencial que se genere y que se moldee el derecho. Esto es muy verdadero para algunos y específicos institutos jurídicos, como la libertad de expresión, el derecho a la propiedad, como también para los regímenes jurídicos en sí, como el derecho interno y el internacional (Piovesan, 2016). Ius Constitutionale Commune para América Latina afirma la real existencia de un nuevo fenómeno jurídico, uno que emergió desde la interacción entre la confluencia de estos dos ámbitos normativos, el doméstico y el internacional, y se distinguió por sus impulsos específicos (Salazar Ugarte, 2014).

El concepto Ius Constitutionale Commune para América Latina da a este nuevo fenómeno jurídico una identidad, provee una orientación y objetiva la generación y la 
estructuración de la comunicación académica, política y judicial. Al dar una denominación a este fenómeno y describirlo bajo un símbolo único, se propone una lectura compartida de esta figura jurídica, doctrinal y académica que, hasta ahora, ha sido explorada de manera fragmentaria. Al llamar a este movimiento Ius Constitutionale Commune para América Latina, se permite que se agreguen personas y proyectos de distintas bases, pero que comparten las mismas creencias en el potencial transformativo de los derechos humanos, de la democracia y del Estado de derecho para América Latina (Von Bogdandy et al., 2011).

Juristas y académicos del derecho pueden hacer la diferencia en la agenda social. América Latina es un gran ejemplo de eso, precisamente en el campo de los derechos humanos. Estos vienen desarrollándose en los últimos treinta años por medio de un lenguaje en común, no solo jurídico, sino también político y social, que no existía antes. No es solamente el lenguaje entre los profesionales del derecho, sino que existe una plataforma de movilización para un público mucho más amplio (Von Bogdandy et al., 2016).

Ius Constitutionale Commune para América Latina es un concepto inclusivo. Todos los autores que están trabajando en esta visión están de acuerdo con que dicha idea no está conectada a ninguna agenda partidista específica. Sin embargo, como cualquier otro concepto legal, no es algo neutral o agnóstico. De hecho, a partir de esta conexión con el constitucionalismo transformativo (Tushnet, 2000), profesa su normatividad y se vuelve parte de un proceso social mucho más amplio. Muchos actores, no solamente juristas, pretenden alcanzar cambios políticos y sociales en la realidad de América Latina creando un marco general para la completa realización de la democracia, el Estado de derecho y de los derechos humanos, haciendo de los países latinoamericanos más diferenciados y cohesionados al mismo tiempo. Por abstracto y confuso que esto pueda parecer en un primer momento, como proyecto se vuelve algo muy concreto y preciso (Von Bogdandy et al., 2016).

Estas breves líneas sobre Ius Constitutionale Commune para América Latina, pueden hacer pensar - y esto es solamente una sugerencia inicial - sobre este concepto fuera de Latinoamérica, teniendo en cuenta este mundo globalizado (Pernice, 2012, p. 11 y ss.). Los desafíos son enormes, y la complejidad puede ser un obstáculo muy difícil. Sin embargo, si se quiere adaptar este proceso de globalización a otras esferas que eviten abordarlo únicamente desde el punto de vista económico y se pueda abrir a otros objetivos, como la real y amplia protección de los derechos humanos, se tienen que encontrar nuevos caminos para analizar dicho panorama. Y es acuciante hacerlo muy rápido, porque viene una enorme ola nacionalista que ya está creciendo en el mundo y se fortalece cada día más.

Este es el gran desafío. 


\section{CONCLUSIONES}

¿Estamos en una nueva era de la globalización o estamos regresando a los sistemas nacionalistas?

Desafortunadamente, las noticias no son buenas sobre globalización, derechos humanos y los nuevos fenómenos democráticos. En muchos sitios del mundo, las personas están apoyando una fuerte agenda nacionalista, con muchos eslóganes discriminatorios, como "tú, extranjero, fuera", "tu lugar no es aquí", o "derechos solo para los nacionales", entre otros. Esto no es bueno ni para los derechos humanos — considerando que todos somos iguales-, ni tampoco para el proceso de globalización fuera de los estándares económicos.

No se puede volver atrás cuando se habla de derechos humanos. Discursos como estos son peligrosos, dañinos, lentamente desgastan todas las conquistas sociales y humanas que fueron alcanzadas. Esto no se puede permitir.

La sociedad del siglo XX fue testigo de enormes transformaciones que hicieron posible el fomento y el incremento de la noción de derechos humanos. Más allá de los derechos de libertad, hay una conciencia ya construida de la necesidad de otros que alcancen las demandas sociales, las que involucran temas difusos y las que aporten paz para los pueblos. Nociones como derecho al desarrollo fueron posibles después de perfeccionar la idea de que no basta la economía para tener condiciones de supervivencia, sino que más bien se hacen necesarios elementos que permitan que las personas puedan disfrutar de una real libertad a partir de la satisfacción de sus necesidades primeras, que son centrales en la concepción utilizada en este artículo. Sin embargo, se pudo observar que el poder de cambio venido desde estas nuevas posiciones globales es enorme e interfiere directamente en el statu quo, que no está interesado en ceder su espacio para que el mundo tenga condiciones más adecuadas de vida.

Es posible creer en un mundo mejor, en un mundo globalizado, democrático e inclusivo. Los juristas tienen el deber de encontrar nuevas soluciones para alcanzar y concretar estos derechos. En el siglo XX se hizo mucho. Se construyó toda la estructura jurídica y legal para hacer grandes cambios en la agenda social. Ahora ha llegado el tiempo de concretarlos, de ponerlos en práctica por medio de una fuerte, amplia y global gobernanza constitucional. La idea de igualdad, interdependencia y complementariedad no puede verse limitada a estructuras jurídicas que ya no corresponden más a este mundo que se presencia. Un derecho común que observe las diferencias inherentes al multiculturalismo y considere a los seres humanos tal y como son, se hace muy importante para afrontar los desafíos que el siglo XXI ya mostró que vendrán. 


\section{REFERENCIAS}

Acosta Alvarado, P. A. (2016). Zombis vs. Frankenstein: sobre las relaciones entre el derecho internacional y el derecho interno. Estudios Constitucionales, 14(1). https://scielo.conicyt.cl/pdf/ estconst/v14n1/art02.pdf

Asamblea General de la Naciones Unidas. (1948, 10 de diciembre). Declaración Universal de los Derechos Humanos. Resolución 217 A (III). http://www.un-documents.net/a3r217a.htm

Asamblea General de la Naciones Unidas. (2008, 10 de diciembre). Protocolo opcional para el Pacto Internacional de Derechos Económicos, Sociales y Culturales. Resolución 63/117. https://www.ohchr.org/ en/professionalinterest/pages/opcescr.aspx

Asamblea General de la Naciones Unidas. (1966, 16 de diciembre). Declaración Universal de los Derechos Humanos. Resolución 2200 A (XXI). https://www.un.org/en/development/desa/population/migration/ generalassembly/docs/globalcompact/A_RES_2200A(XXI)_civil.pdf

Aguilar, J. y Carranza, M. (2008). Las maras y pandillas como actores ilegales de la región [ponencia], San Salvador, El Salvador.

Almeida, P. W. y Pereira, M. F. L. (2013). Revisitando os efeitos da assinatura de um tratado internacional: da obrigação de boa-fé à sujeição internacional do estado. Revista Direito GV, 9(1), 171-197.

Barros, A. T. (2018). A Esquerda Verde: Partidos Políticos e Ambientalismo Radical no Brasil. Dados, 61(2), 503-540.

Bauman, Z. (1999). Globalização: as consequências humanas. Zahar.

BBC News. (2018, 26 de noviembre). Migrant caravan: What is it and why does it matter? https://www.bbc. com/news/world-latin-america-45951782

Beck, U. (2008). ¿Qué es la globalización?: Falacias del globalismo, respuestas a la globalización. Paidós.

Black, R. (2001). Environmental refugees: myth or reality? Acnur. https://www.unhcr.org/research/ working/3ae6a0d00/environmental-refugees-myth-reality-richard-black.html

Cambiaghi, C. T. y Vannuchi, P. (2013). Sistema Interamericano de Direitos Humanos (SIDH): reformar para fortalecer. Lua Nova: Revista de Cultura e Política, (90), 133-163.

Chiam, M. (2018). Monism and dualism in International Law. http://www.oxfordbibliographies.com/view/ document/obo-9780199796953/obo-9780199796953-0168.xml

Comisión Interamericana de Derechos Humanos, CIDH. (2017). Estadísticas. http://www.oas.org/es/ cidh/multimedia/estadisticas/estadisticas.html

Corte Interamericana de Derechos Humanos, Corte IDH. (1999). Sentencia de 24 de septiembre para el caso del Tribunal Constitucional.

Corte Interamericana de Derechos Humanos, Corte IDH. (2005). Sentencia de 11 de marzo para el caso Caesar vs. Trinidad y Tobago.

Crawford, J. (2012). Brownlie's Principles of Public International Law. (8. ${ }^{a}$ ed.) Oxford University Press.

Gorczevski, C. y Dias, F. da V. (2012). A imprescindível contribuição dos tratados e cortes internacionais para os direitos humanos e fundamentais. Sequência (Florianópolis), (65), 241-272. 
Habermas, J. (2001). A constelação pós-nacional: Ensaios políticos. Littera.

IJRC. (S.f.). Interamerican Human Rights System. Consultado el 28 de mayo de 2019. https://ijrcenter.org/ regional/inter-american-system/\#Inter-American_Commission_on_Human_Rights

Jarillo Aldeanueva, A. (2001). Globalización: Concepto y papel del Estado. UNED: Boletín de la Facultad de Derecho, 18, 215-231.

Kelsen, H. (1965) La unidad entre el Derecho internacional y el Derecho interno. Revista de la Facultad de Derecho y Ciencias Sociales. 3-4, 377-397.

Konhad Adenauer Stiftung. (2001). Preface. Globalization and constitutionalism. Consultado el 28 de diciembre de 2018. https://www.kas.de/c/document_library/get_file?uuid=997c94e0-2b85-b6bbc27e-4187f03201d0EgroupId $=252038$

Laclau, M. (2014). Soberanía y Estado de derecho. Astrea.

Losano, M. G. (2002). Kelsen y Campagnolo: una controversia de derecho internacional entre la paz y la guerra. Revista de la facultad de derecho, 21, 209-224.

Martínez Hernández-Mejía, I. (2018). Reflexiones sobre la caravana migrante. Análisis Plural, primer semestre. Consultado el 14 de febrero de 2020. https://rei.iteso.mx/bitstream/handle/11117/5616/ S3\%20Reflexiones\%20sobre\%20la\%20caravana\%20migranteAjustado.pdf?sequence $=2$

Martínez Morán, N. (2008). Mundialización y Universalización de los Derechos Humanos. En B. de Castro Cid y N. Martínez Morán, (eds.). 18 lecciones de Filosofía del Derecho (pp. 211-224). Editorial Universitas.

Marx, K. (2003). O capital (2. ${ }^{a}$ ed.). Edipro.

Neves, M. (2003). A Força Simbólica dos Direitos Humanos. Revista Brasileira de Direito Público RBDP (Belo Horizonte), 3(1), outubro/dezembro.

Neves, M. (2009) Transconstitucionalismo. WMF Martins Fontes.

Organización de Estados Americanos, OEA. (S.f.) Comisión Interamericana de Derechos Humanos. Consultado el 27 de septiembre de 2019. https://www.oas.org/es/acerca/comision_derechos_humanos.asp

Pernice, I. (2012). La dimensión global del Constitucionalismo Multinivel: una respuesta legal a los desafíos de la globalización. Fundación Universitaria San Pablo CEU.

Piovesan, F. (2016). Ius Constitutionale Commune em Direitos humanos e Constitucionalismo regional transformador: o impacto do Sistema Interamericano. En A. Von Bogdandy, M. Morales y F. Pioveasan, Ius Constitutionale Commune na América Latina (pp. 75-95). Juruá.

Piovesan, F. (2017). Ius constitutionale commune latino-americano em Direitos Humanos e o Sistema Interamericano: perspectivas e desafios. Revista Direito E Práxis, 8(2), 1356-1388.

Primera, M. (2013, 10 de septiembre). Venezuela abandona el sistema de derechos humanos interamericano. El País. https://elpais.com/internacional/2013/09/10/actualidad/1378780644_769381.html

Rivero, M. (2013, 10 de septiembre). CIDH manifiesta su profunda preocupación por efecto de la denuncia de la Convención Americana por parte de Venezuela. Comunicado de prensa CIDH. http://www.oas.org/es/ cidh/prensa/comunicados/2013/064.asp 
Rodríguez Martínez, E. (2012). Globalización jurídica y su impacto en el derecho interno. Opinión Jurídica, 11(22). https://revistas.udem.edu.co/index.php/opinion/article/view/581

Salazar Ugarte, P. (2014). La reforma constitucional sobre derechos humanos. Un guía conceptual. Instituto Belisario Domínguez.

Sánchez Lorenzo, J. (2017). El multiculturalismo y la autodeterminación en el ámbito de los derechos humanos. Revista de la Facultad de Derecho, 43, 199-233.

Santano, A. C. y Pereira, R. V. (2015). Uma aproximação aos europartidos no marco jurídico-político da união europeia: rumo a uma maior integração regional. Revista Direitos Fundamentais \& Democracia (UniBrasil), 18, 123-145.

Toro Huerta, M. I. (2005). La apertura constitucional al derecho internacional de los derechos humanos en la era de la mundialización y sus consecuencias en la práctica judicial. Boletín Mexicano de Derecho Comparado, XXXVIII(112), 325-363.

Trindade, A. A. C. (1997). Dilemas e desafios da Proteção Internacional dos Direitos Humanos no limiar do século XXI. Revista Brasileira de Política Internacional, 40(1), 167-177.

Tushnet, M. (2000). Taking the Constitution Away from the Courts. Princeton University Press.

UN News. (2018, 13 de febrero). Causes of Rohingya refugee crisis originate in Myanmar; solutions must be found there, Security Council told. https://news.un.org/en/story/2018/02/1002612

Valim, R. (2011) Apontamentos sobre os direitos sociais. En A. C. Malheiros, J. Bacariça y R. Valim, (coords.). Direitos humanos: Desafios e perspectivas (pp. 173-180) . Fórum.

Vásquez, F. J. (1). Impacto de la globalización en el mundo jurídico. Opinión Jurídica, 8(15). https:// revistas.udem.edu.co/index.php/opinion/article/view/759

Von Bogdandy, A., Ferrer, E., Morales, M., Piovesan F. y Soley X. (2016). Ius Constitutionale Commune en América Latina: A Regional Approach to Transformative Constitutionalism. Research Paper n. ${ }^{\circ}$ 2016-21. Max Planck Institute for Comparative Public Law \& International Law (MPIL). https://papers.ssrn. com/sol3/papers.cfm?abstract_id=2859583

Von Bogdandy, A., Fix-Fierro, H., Morales Antoniazzi, M., Ferrer Mac-Gregor, E. (eds.). (2011). Construcción y Papel de los Derechos Sociales Fundamentales. Hacia un Ius Constitutionale Commune en América Latina. Instituto de Investigaciones Jurídicas. 